\title{
COUNTERPOINT: Are surgeons ethically obligated to treat Medicare patients despite substantial reductions in reimbursement?
}

Tea E. Acuff, MD

See related articles by Robert M. Sade on pp 37 and Edward D. Verrier on pp 38-40.

I was probably 5 years old. In those days we played with little adult direction. I preferred to run with older boys, and my slightly older elders were teaching me the lessons of marbles. I put my new bag of marbles in the ring, but one of the older boys put in a single "cat eye" marble. "It is worth 50 marbles," he explained. So I learned the rules and techniques for playing marbles. Later I had developed both enough skill and the opportunity to knock the valuable "cat eye" out of the circle we had drawn in the dirt. When I sought out a return of some of my marbles now owned by others in exchange for the valuable "cat eye," a nuance of the game of marbles was revealed to me. The "cat eye," now in my possession by the rules, was worth only a few marbles. I never played marbles again with my friends.

Does this childrens' game of marbles have lessons for the adults' game of medicine? The former is more simple and transparent, which should allow us to expand that view to the more complex problem of our debate.

There are basically 2 general ways to view this boys' game of marbles. One is to focus on the game itself with the rules, players, and performance. This might be the way an adult would instruct the game, by teaching the rules, techniques, and fair play. We might call this a "closed" or teacher system, since we as the adult more or less know the right answers to simple games like marbles or dice and can instruct the boys as to right and wrong performance, information, or ethics. I take the form of our debate to conceptually be a "closed" system.

An alternative approach would be not to focus on the game of marbles as the baseline, but to focus on the

\footnotetext{
From the Heart Hospital at Baylor Plano, Plano; the Department of Cardiothoracic Surgery, Denton Regional Medical Center, Denton; and the Cardiopulmonary Research Science and Technology Institute, Dallas, Tex.

Disclosures: Author has nothing to disclose with regard to commercial support.

Read at the 92nd Annual Meeting of The American Association for Thoracic Surgery, San Francisco, California, April 28-May 2, 2012.

Received for publication Sept 13, 2012; accepted for publication Sept 24, 2012.

Address for reprints: Tea E. Acuff, MD, 3333 Colorado Blvd, Denton, TX 76210

(E-mail: tacuff@swbell.net).

J Thorac Cardiovasc Surg 2013;145:41-3

$0022-5223 / \$ 36.00$

Copyright (c) 2013 by The American Association for Thoracic Surgery

http://dx.doi.org/10.1016/j.jtcvs.2012.09.066
}

interaction of the boys. In this view, the system is more "open" and the "game" played is self-organizing. This bigger game is not about marbles or ethics per se but about learning how to interact with games and people to reach the ultimate goal. In this case, the ultimate goal is how to compete for marbles. In this scenario, the rules to a game of marbles are more malleable, and the strategies of the boys are not restricted to the playing surface. Ideas of fairness or ethics are likewise less restricted to specific categories of behavior but are broad based or system dependent. Performance and ethics are not clearly distinguishable. The most straightforward approach may lose in the long run. You may get more marbles playing many less predictable games with a lesser opponent than one game of more certain outcome. I argue the "open" systems are more representative of real life. After all, the Yankees always end up with the best players, no?

Biologist Gregory Bateson ${ }^{1}$ quipped that "any school boy ought to know" that the logic commonly used in linear or closed systems leads to paradox in open systems. Ideas in nature, biologic systems in Bateson's cybernetic view, emanate from the whole, not from a particular part of a system, even the "thinking parts." Meaning is more than a sum of the parts. Idea is superposed to the parts.

And paradox abounds in our medicine, as Bateson suggested. I am not referring to the obvious things that we do not know, but to the things we say that we do know. Ideas that we are very sure, statistically speaking, are true. This paradox is, at least in part, because we discuss open systems with the logic or language of closed systems. ${ }^{2}$

Take for example our beloved risk-adjusted databases on which we hope to base our most important policies and punishments. A peer-reviewed report found that coronary artery bypass graft surgery in the decade of the 1990s demonstrated that mortality declined in the face of climbing risk. ${ }^{3}$ Not only do the authors believe this, but most of us believe we are operating on sicker patients without worsening mortality. If this is so, what do we mean by risk in real patients? How does risk increase in the face of declining mortality? What do we mean by risk? The self-congratulatory explanation given was that we are doing a good job.

If we step back from this explanation as we did in the marble game, we may have a more "open" view of what is happening. The game is changing. Logically, mortality should not go down while its risk goes up. Now it may be that we do a better job, but we must remember this is a system and other parts also play role. The explanation for both the complexity of the patients and our decreasing surgical 
mortality is likely spread across the medical system. Just as price in the supply/demand curve is neither strictly a function of supply cost or consumer demand, our declining cardiac mortality is not just that we do a better job. We certainly cannot define risk in terms of patients by looking merely at the mortality from patients selected for procedures. If we do, risk will likely be paradoxical. (We could, for example, have found that both risk and mortality went up or both went down, but then this may not have been directly related either.)

If we are to know the true causes of risk, we must know the denominator(s). We must also study patient access, patients turned down, and patients offered and selecting other modalities of therapy if we seek the real risk and benefits of surgery. It may be that we have little to do with declining mortality over the past few years. Certainly adding mitral repairs, patent foramen ovale closures, or left ventricular assist devices to various stages of coronary artery bypass grafting do not help us decide what coronary bypass risk is either by our databases. What is clear is that risk for coronary artery bypass grafting cannot be understood strictly from our patients selected any more than a stock's performance can be determined from the previous results.

In a related postprocedure analysis peer report, it has been claimed that mortality is overestimated in the right or high-risk side of our database risk curves. ${ }^{4}$ Ironically, we are led to believe that low-risk mortality on this same curve is more predictable and that we will soon come up with better high-risk predictions. Again, this seems to be a paradox of an open system confused by logic from a closed perspective. If a particular population yields a particular total mortality, how can it be true that the high-risk side is overestimated but the low-risk side is correct? Where did the mortality go? There are no patients that die $1 \%$ or $10 \%$ of the time. Patients either die or they do not. We are just not as good at prediction as we think at any point of the curve. By what theory do we proclaim half of the information for a population correct and the other false? Whatever we think of the death or survival of a patient based from these database analyses starts with a bias.

Unfortunately, we have used our self-congratulatory predictability to justify high profile and high dollar research. We select "inoperable" or high-risk patients for high-risk trials. Although my argument is not that alternative therapy including interventional techniques are not worth testing or even that there is no such thing as risk, we must not use our fixed notions of risk or predictability to either preclude real world applications or demand excessive funding for definitive research. Our paradoxical views of risk and competence now demand nearly a billion dollars for successful testing of novel drugs and devices. On the other hand, neochords transformed both approaches to and surgeons available to mitral valve repair after a few animal trials and master surgeon adoptions. It seems to me that the transapical aortic valve implantation approach has much more the hallmarks of a "closed" system and the neochords that of an "open" system. In the bigger picture, which was better use of our resources?

The closed system mentality also leads to the paradox of expert guidelines. By both process and design, guidelines are developed by those that have pushed the envelope of old guidelines. So we are espousing and regulating a closed system by those who practice primarily in an open system. The real question is whether we defend and support surgeons who mimic those experts that seek the new or superimposed logic of an open system or condemn surgeons to follow the logic of the guidelines of a system closed behind the free action of the experts. Will the real leaders stand up and tell whom they wish surgeons to be?

Of course, there is the rub. The same surgeon who would be the teacher in a closed system is the surgeon learner in an open system. Although it might be reasonable to call this a paradox, perhaps a choice may be more accurate. Either way, the surgeon chooses his reality and results. He does not "find" it projected into his results. This choice paradox is more transparent in purpose, and where intent or reason is posited in a system matters. It also likely is more robust in its predictability inasmuch as the signal of appropriateness is openly chosen and not hidden in the post hoc expert opinion. $^{5}$

I now come to the crux of my defense of the surgeon who opts out of Medicare. We can see how medical thought leaders have preferred the role of teacher in a closed system to that of expert learner in an open system. As one among peers, even expert learners in an open system have no intrinsic distinction above other players on the field. Experts as leaders play the same game as we all do in open systems, even if they may as experts more often do it better. In an open system, the teacher is at best an expert learner. If there are prescribed areas of teaching, it may be clearly defined. Closing the system to elevate some peers to teacher subjects the rest of us to paradox of the teacher-defined system.

The facts in this debate on Medicare are not in question and are largely agreed to by both sides. The question is how to view the facts. I argue the answer comes from the way we ask the question. Those that answer for others close the system, as do teachers with determinate answers.

Medicare as a payment system today is a massive transfer of wealth from the poorest quintiles of our population to the wealthiest. All agree to that. It is just that some want to transfer more wealth to all age groups if this might be possible. Medicare's age of 65 years and older is roughly both the oldest and most wealthy quintile of our population.

The origin of the logic to this wealth transfer is more circuitous. Medicare was designed in a different era to provide funding for medical care to those no longer employed. This idea in turn was partially (and anachronistically) the result 
of our tax policy that shifted medical insurance and benefits to an employer tax neutral expense and not to after-tax employee dollars. This small leverage in the past created a presently large imbalance inasmuch as Medicare has become its own closed political game. Medicare thus arose as a way to provide access to physicians to those without the leverage of employer insurance. Yet my debate opponent, now inured to paradox, considers it mandatory that physicians accept Medicare funding even if it leads to their insolvency. Medicare, which was designed to make mainstream physician services available, is now destined to take physicians out of the main stream. This sounds like a paradoxical position to me. It also seems unreasonable and self-serving of those who, at this point, seem immune to those consequences.

Medicare is now, or will soon be, economic nonsense. Even some 5-year-old boys might recognize that truth.
But doctors are good at understating reality in their favor. "This may be a little uncomfortable," we are fond of saying about real pain. Patients have come to expect nothing less from us. And nothing more. We must again expect more from ourselves.

\section{References}

1. Bateson G. Mind and nature: a necessary unity. New York: Bantum Books; 1979.

2. Jayasinghe S. Complexity science to conceptualize health and disease: is it relevant to clinical medicine? Mayo Clin Proc. 2012;87:314-9.

3. Ferguson TB Jr, Hammill BG, Peterson ED, DeLong ER, Grover FL, STS National Database Committee. A decade of change-risk profiles and outcomes for isolated coronary artery bypass grafting procedures, 1990-1999: a report from the STS National Database Committee and the Duke Clinical Research Institute. Society of Thoracic Surgeons. Ann Thorac Surg. 2002;73:480-9.

4. Mack MJ. Risk scores for predicting outcomes in vascular heart disease: how useful? Curr Cardiol Rep. 2011;13:107-12.

5. Brook HW. American gridlock: why the right and the left are both wrongcommon sense 101 solution to the economic crisis. Hoboken: John Wiley; 2012. 